\begin{tabular}{|c|c|c|}
\hline Port Said Engineering Research Journal \\
\hline
\end{tabular}

\title{
Fault Detection for Extra High Voltage Lines Using Modified Wavelet Transform
}

\author{
A. M. Hamada', M. I. Yahia' , S. M. Moussa ${ }^{3}$, H. E. Mostafa ${ }^{4}$ \\ ${ }^{1}$ Helwan University, Faculty of industrial education, Dept. of Electrical, Cairo, Egypt \\ ${ }^{2,4}{ }^{4}$ Suez Canal University, Faculty of Industrial Education, Dept. of Electrical, Suez, Egypt \\ ${ }^{3}$ Helwan University, Faculty of engineering, Dept. of Electrical Power and Machines, Cairo, Egypt
}

\begin{abstract}
:
This paper presents a new approach of fault detection for EHV transmission lines using one-end data for either of voltage or current signals. The scheme is based on the use of modified wavelet transform and implementation of digital signal processing concepts for the experimental results. A modified wavelet function is used to analyze the high frequency components initiated by the abnormal conditions. The algorithm is evaluated using the alternative transient program ATP model of $500 \mathrm{KV}, 300 \mathrm{Km}$ transmission line. The obtained results indicate an accepted degree of accuracy for the suggested technique. In addition, the new form of wavelet function is implemented in the real time model to detect any sudden changes in the voltage signal due to fault occurrence through the line.
\end{abstract}

Key words: EHV transmission lines, high frequency noise, fault detection technique, wavelet transform, ATP.

\section{I- INTRODUCTION}

The most common sources of transients in power systems are due to line and load switching or fault occurrence. These transients are initiated by a sudden change in the circuit conditions. The changes occur when the existing current path is isolated or a new one is introduced. During this, a high frequency noise is introduced on the lines. It is certain that, the high frequency components associated with the fundamental one, on the transmission lines, are containing some information about the fault [1]. In order to detect the high frequency components, several algorithms have been used in power systems, such as the Fast Fourier Transform, the Kalman filtering, the Least Square method, and Finite Impulse Response filtering [2,3,4]. However, in presence of non stationary signals, the performance of these algorithms has some limitations. The Wavelet Transform is one of the mathematical tools for analyzing the Nonstationary signal in both time domain as well as frequency domain, by means of dilating and translating a single function named mother wavelet [5]. Wavelets have been successfully applied in many areas of signal processing in many applications such as, image processing, speech processing, and data compression [6]. Up to date, in power system the wavelet transform may be employed either for analyzing records and simulations, or in real time operation for protection devices [7, 8]. A technique using wavelet analysis filter bank to identify distribution high impedance faults is presented in [7]. In [8], wavelets are used to separate high frequency component associated with the fundamental frequency, so that, most of the high speed relay algorithms utilize the high frequency component to make a protective decision. Also, wavelet transform with a new complex wavelet is utilized to quantify short duration power quality disturbances. [9].
The experimental system introduces a real time digital environment based on Lab View package [10]. A complete hardware including signal measurements, signal processing and programming language is built in around the Lab View Package. The laboratory model is examined under the healthy and faulty conditions in order to study its performance.

In this paper, the integral wavelet transform is modified and implemented to detect the high frequency noises that introduced on the EHV lines due to abnormal conditions such as faults and switching. The wavelet transform uses the instantaneous values of voltage signal accessible at one end.

\section{II- BASIC WAVELET FUNCTION}

The basic wavelet function " $\psi(t) "$ is a very fast decaying oscillating wave. This wave is described by:

$$
\psi(t)= \begin{cases}\left(1+\sigma \mathrm{t}+\frac{\sigma^{2}}{2} \mathrm{t}^{2}\right) \mathrm{e}^{-\sigma \mathrm{t}} \mathrm{e}^{\mathrm{i} \mathrm{w}_{\mathrm{o}} \mathrm{t}} & \mathrm{t}>=0 \\ \left(1-\sigma \mathrm{t}+\frac{\sigma^{2}}{2} \mathrm{t}^{2}\right) \mathrm{e}^{\sigma \mathrm{t}} \mathrm{e}^{\mathrm{iw_{ \textrm {o } } \mathrm { t }}} & \mathrm{t}<=0\end{cases}
$$

where $\quad \mathrm{w}_{0}=2 \pi f, \quad \sigma=2 \pi / \sqrt{3}$

Fig. 1 shows the real part of the basic wavelet of 50 $\mathrm{Hz}$ frequency. This basic wavelet is an even function with approximately effective five cycles of $0.1 \mathrm{sec}$. width. The wavelet has the following properties, fast damped oscillating wave, identical around zero time and the integration over its life time is zero. 


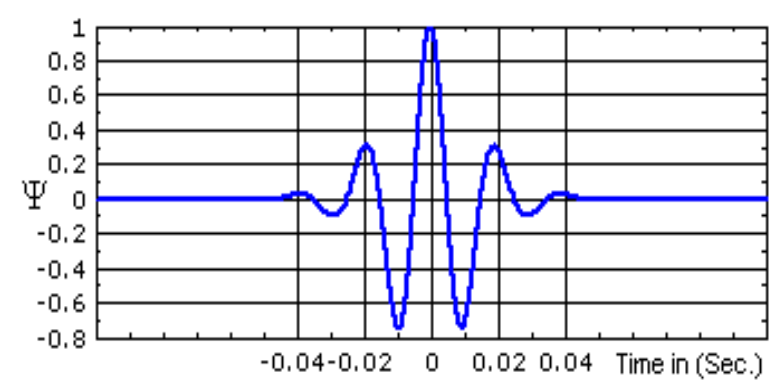

Fig. 1 Real part of basic wavelet

\section{III- MODIFIED WAVELET FUNCTION}

The original wavelet presented in equation (1) needs at least 15 points in order to be described. In such case, the wavelet function requires a hard computational effort to be done. A simple modification is suggested by authors to represent the wavelet by less numbers of points as mention on equation (3). It is clear evident that, the integration of modified wavelet must be zero as following:

$$
\int_{-\infty}^{+\infty} \Psi(\mathrm{t}) \mathrm{dt}=0
$$

Equation (3) describes the modified wavelet represented by five points only, three of them are zero, which reduce the computational effort for calculating the wavelet function. Fig. 2 shows the modified wavelet.

$$
\psi(t)=\left\{\begin{array}{cc}
t & -1 \leq|t| \leq 1 \\
(2-t) & 1 \leq|t| \leq 2 \\
(-t-2) & -2 \leq|t| \leq-1 \\
0 & \text { otherwise }
\end{array}\right.
$$

In this case, the overall integration of this modified function still produces zero average value as following:

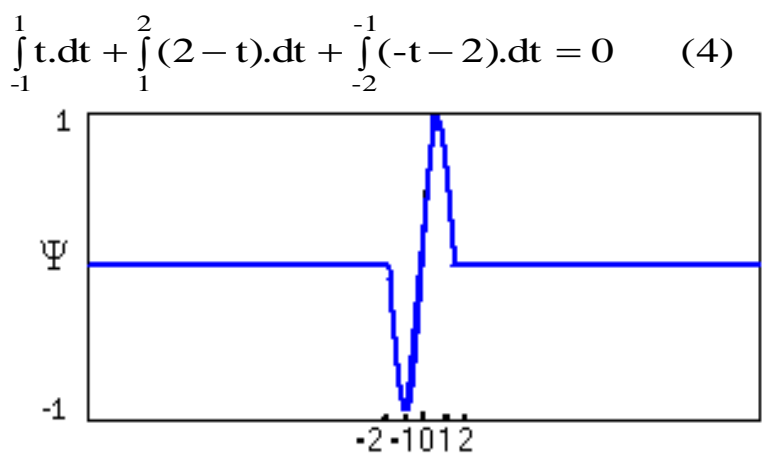

Fig. 2 Modified wavelet function

The modified wavelet function S(i) based on the healthy voltage waveform is calculated as following:

$$
\begin{aligned}
& \mathrm{s}(\mathrm{i})=\mathrm{v}(\mathrm{i})-\mathrm{v}(\mathrm{i}+1) \\
& \mathrm{v}(\mathrm{i})=\cos (\mathrm{w} * \mathrm{i} * \Delta \mathrm{t})
\end{aligned}
$$

Where, $v(i)$ is the voltage signal for healthy waveform and is obtained in per unit, $\Delta \mathrm{t}$ is the sampling time interval in sec.

\section{IV- SELECTING THRESHOLD VALUE}

In normal condition, wavelet function s(i) always lies around zero value and it deviates from zero during fault condition. The magnitude of this signal depends on many factors such as fault type, fault location, fault inception angle and processing sampling rate. Therefore selecting a predetermined threshold limit, valid for all conditions, becomes tricky. The authors suggest a predetermined threshold limit $(\rho)$ taken equal to 1.05 like others [11] and [12]. It is sufficient to detect all fault conditions as;

$$
|\mathrm{s}(\mathrm{i})|>\rho
$$

\section{V- STUDIED SYSTEM}

The system shown in Fig.(3) is ATP simulation for selected power system to evaluate the suggested techniques. The calculation required to calculate the modified wavelet function is carried out using $\mathrm{m}$ file build on MATLAB program. The system represents an actual extra high voltage transmission line of $500 \mathrm{kv}$ and $300 \mathrm{~km}$ long. Table 1 shows the resistance, inductance and capacitance values of the line per $\mathrm{km}$. These values are the typical $\pi$ section model of the transmission line. The sampling frequency of the voltage signals and the wavelet function is choice to be $100 \mathrm{KHz}$ which is a reasonable. Higher rate gives more accurate fault detection but consumes more processing time.

\section{TABLE I: LINE PARAMETERS}

\begin{tabular}{|cc|c|c|}
\hline \multicolumn{2}{|c|}{ Parameter } & Value & Dimension \\
\hline Resistance & $\mathrm{R}$ & 0.0217 & $\mathrm{Ohm} / \mathrm{km}$ \\
\hline Inductance & $\mathrm{L}$ & $9.61 \times 10^{-4}$ & $\mathrm{H} / \mathrm{km}$ \\
\hline Capacitance & $\mathrm{C}$ & $1.26 \times 10^{-8}$ & $\mathrm{~F} / \mathrm{km}$ \\
\hline
\end{tabular}

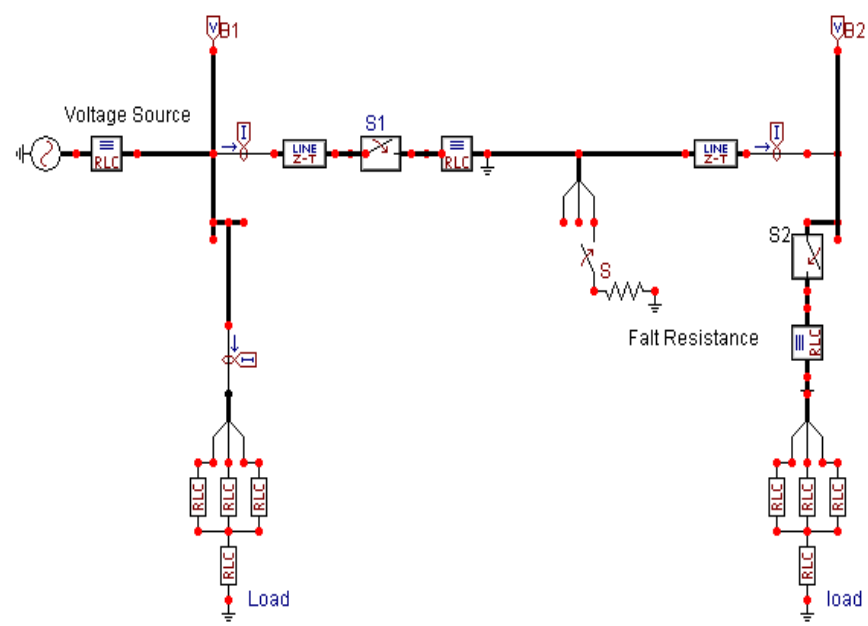

Fig. 3 The study system

\section{VI -COMPUTER SIMULATION}

In order to investigate the applicability of the proposed wavelet transform fault detection algorithm, extensive simulation studies are done, only four study cases are presented. These cases compute of various fault conditions at single line to ground fault SLG. The aim of these cases is to check the algorithm accuracy for fault 
detection. In each case study the voltage wave-forms are presented.

\section{A. Fault Conditions Effect}

In the first study case (Case study 1: Close-up fault), the fault is done at a distance of $5 \mathrm{~km}$ at SLG through a fault resistance of $20 \mathrm{ohm}$. Fig (4-a) shows the voltage wave-form at bus B1 and Fig. (4-b) shows the output of the modified wavelet function.

The same sequence is done for the second study case (Case study 2: remote-end fault), where the fault accurse at distance $290 \mathrm{~km}$ through a fault resistance of $20 \mathrm{ohm}$. Fig. (5-a), (5-b) shows the same values as fig. 4.

Cases studies 3 and 4 present the effect of fault resistance where the fault is done at the mid-point of the line through a fault resistance of $10 \mathrm{ohm}$ and $100 \mathrm{ohm}$ to show the accuracy of the suggested technique for the high impedance faults. Fig. 6 and fig. 7 show the simulation results and technique evaluation for these cases.

From those results, it is clear that, the magnitude of the high frequency noise changed from faulted case to another according to fault conditions, any sudden changes in the voltage signal can be observed even in the condition of low inception angle and remote end faults that are through a high fault resistance. The detection time instant for faults at $5 \mathrm{~km}, 290 \mathrm{~km}$, and $150 \mathrm{~km}$ are calculated using sampling frequency of the voltage signals is $20.03 \mathrm{~ms}, 20.85 \mathrm{~ms}$, and $20.55 \mathrm{~ms}$ respectively. It is to be noted that, for fault occurred at $20 \mathrm{~ms}$ the results indicate that the detection time is directly proportional to the fault location.

\section{B. Other Transient Conditions}

Transient may be also initiated due to other cases such as switching operations and load or source variations. Discrimination between the high frequency noise initiated due to such reasons and those due to direct faults becomes very essential. These results indicate that the frequencies initiated due to switching are totally differ than those initiated due to faults. Fig. 8 shows the simulation results for line energizing by switching at point S1.

Load switching also is examined by closing the switch at point $\mathrm{S} 2$ on a heavy load. The same concepts for line energizing are true for the load switching as shown in fig. 9 .

\section{VII.TECHNIQUE EVALUATION USING EXPERIMENTAL RESULTS}

\section{A. Experimental Setup}

The hardware implementation is required to demonstrate the ability of the on line implementation of the suggested technique in real time. Fig 10 shows the overall experimental setup. In this figure, the laboratory model consists of four pi section where their resistance, inductance and capacitance as lumped parameters for each section are $(0.195 \Omega, 0.675 \mathrm{~h}, 1.5 \mu \mathrm{f})$, respectively. The transmission line model is introduced with the data acquisition system that based Lab-View environment is presented. The data acquisition card receives voltage signals through voltage transformers with a ratio of 220/3. The voltage signals are fed to the data acquisition card linked with PC-P4 2.8GHz cor2due processor.

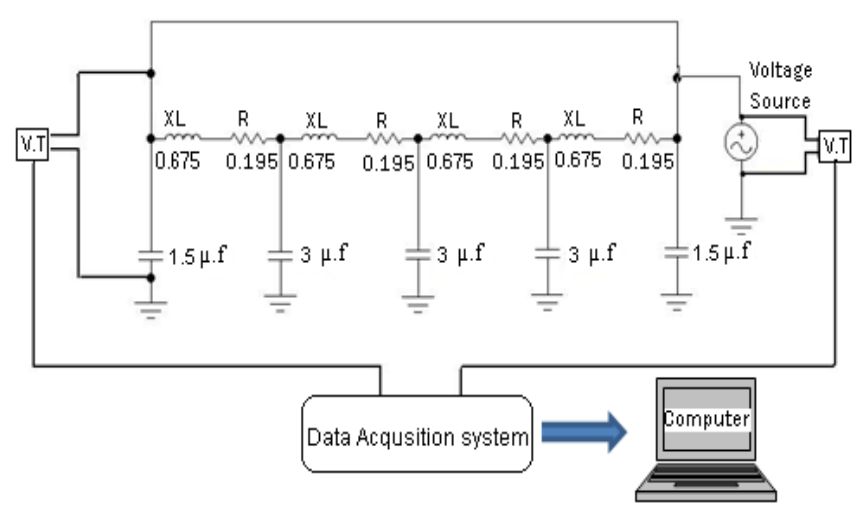

Fig.10 Overall experimental setup

\section{B-Software Structure}

One of the advantages of lab-view package is supported software using graphical programming language. This may be described by more details for convenience as following.

Front panels contain various types of control and indicators that are input and output respectively. Block diagrams contain terminals corresponding to front panel. Controls and indicators as well as consists of functions, sub virtual instruments, structures and wires that carry data from one object to another.

\section{C-Experimental Evaluation of the Modified Wavelet technique}

The experimental results of the laboratory investigation of the fault detection based wavelet transform using the modified function are outlined. The laboratory model is used to produce real signals during fault occurrence.

An extinction series of real time implementation studies has been done using the laboratory model. figures (11, 12 and 13) shows the front panel of lab-view system during fault condition indicating the voltage signals, output of the modified wavelet function s(i), accumulated value of s(i) and trip signal. These figures present three different cases of fault detection due to single line to ground fault, set at $25 \%$ of transmission line, through a fault resistance $20 \Omega, 50 \%$ of transmission line, through a fault resistance $15 \Omega$ and $75 \%$ of transmission line, through a fault resistance $10 \Omega$ respectively.

It is clear that, the outputs of the WT are depending upon the frequency contained of the voltage signal. The outputs signals that are around zero values during normal operation considerably deviate from zeros when the fault occurs. The suggested tool succeeds to extract and detect 
the high frequency components associated with faults. The comparison between the simulation results and experimental results are difficult due to the limited possibilities of the laboratory model. Moreover, the experimental results demonstrate the capability of practical implementation of suggested tool.

\section{VIII- CONCLUSION}

This paper introduced a simplified method for quick and reliable fault detection through EHV transmission line of $500 \mathrm{KV}$ and $300 \mathrm{Km}$ long. The suggested technique distinguishes fault cases from other disturbances even with the condition of low inception angle and remote end fault, which are through high fault resistance up to $100 \Omega$. The experimental tests for evaluating the suggested method indicates accepted accuracy. A basic wavelet function is introduced and modified in order to reduce the computational effort required to calculate the wavelet transform. The modified wavelet function is successfully implemented to detect the fault. The results indicate that, the processing time reduced to less than $50 \%$ compared with other methods using the wavelet function. The reduction of the computational time is one of the most advantages gained.

\section{REFERENCES}

[1] M. M. Eissa, M. Masoud, E. H. Shehab-Eldin \& S. M. Moussa "Detection of High Frequency Noise on Transmission Lines" MEPCON 2000, Ain Shams University, Egypt, 2000.

[2] E. Perez, J. Barros "An extended Kalman filtering approach for detection and analysis of voltage dips in power systems" IEEE Trans. on Power Delivery, vol.72, No.2, pp.147-155, 2004.

[3] Thip Manmek "Real-Time Power System Disturbance Identification and its Mitigation using an Enhanced Least Squares Algorithm" PHD Thesis, University of New South Wales, 2006.

[4] P. Bastard, P. Bertrand, T. Emura, and M. Meunier " The Technique of Finite-Impulse Response Filtering Applied to Digital Protection and Control of Medium Voltage Power System" IEEE Trans. on Power Delivery, Vol. 7, no. 2, PP 681-684,2002

[5] Johan Driesen and Ronnie Belmans "TimeFrequency Analysis in Power Measurement Using Complex Wavelets" IEEE Trans. on
Power Delivery, Vol. 84, No. 4, pp.523-540, 1996.

[6] E. S. Hong, R. E. Ladner \& E. A. Riskin "Group testing for image processing and data compression using wavelet transforms" SCIENCE DIRECT Electrical Power and Energy System, 29, pp. 561-574, 2007.

[7] I. Baqui, I. Zamora, J. Mazón \& G. Buigues "High Impedance Fault Detection Methodology Using Wavelet Transform and Artificial Neural Networks" IEEE Trans. on Power Delivery, vol.81, No.7, pp.1325-1333, 2008.

[8] Maamoon. F and Nagham .H "Disturbance Performance Improvement of Distance Relay with Aid of Wavelet" The 7th International Multi-Conference on Systems, Signals and Devices, pp. 978-985, 2010.

[9] Chen Xiangxun "Wavelet-Based Detection, Localization, Quantification and Classification of Short Duration Power Quality Disturbances" IEEE Trans. on Power Delivery, vol.71, no.3, pp.931-936, 2010.

[10]L.V Lab-VIEW version 8.5, August 2007 for Windows Vista/XP/2000 Users' Manual.

[11]D. Mourad "digital transmission lines unit protection using distance measurement" B.S.C thesis, university of Helwan 2009.

[12] A. M. El-Zonkoly and H. Desouki "Wavelet Entropy Based Algorithm for Fault Detection and Classification in FACTS Compensated Transmission Line" International Journal of Electrical Power \& Energy Systems, vol.33, issue 8, pp.1368-1374, 2011. 

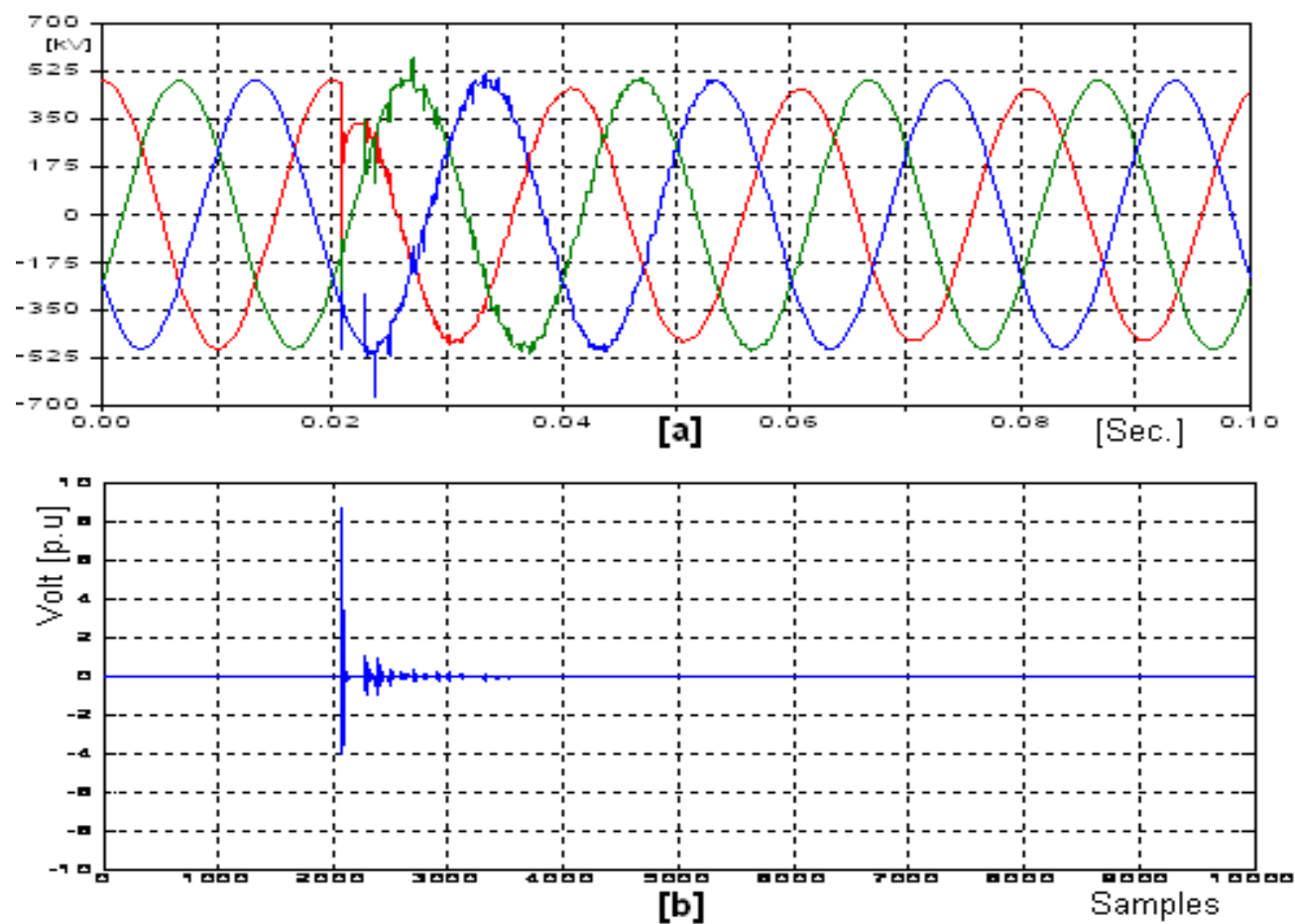

Fig.4 Simulation results for case study 1: Close-up fault Voltage waveform at B1
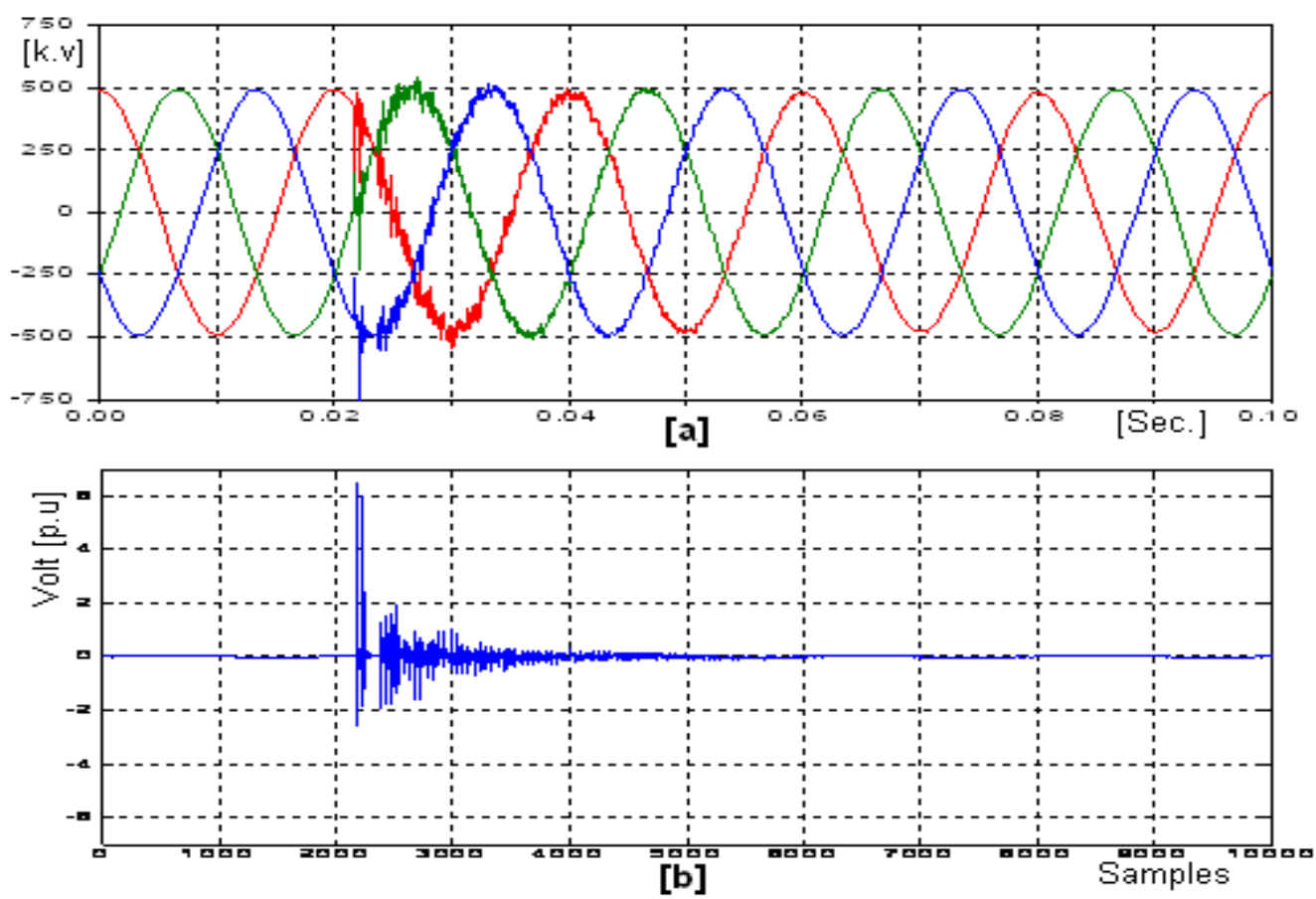

Fig.5 Simulation results for case study 2: Remote-end fault Voltage waveform at B1 

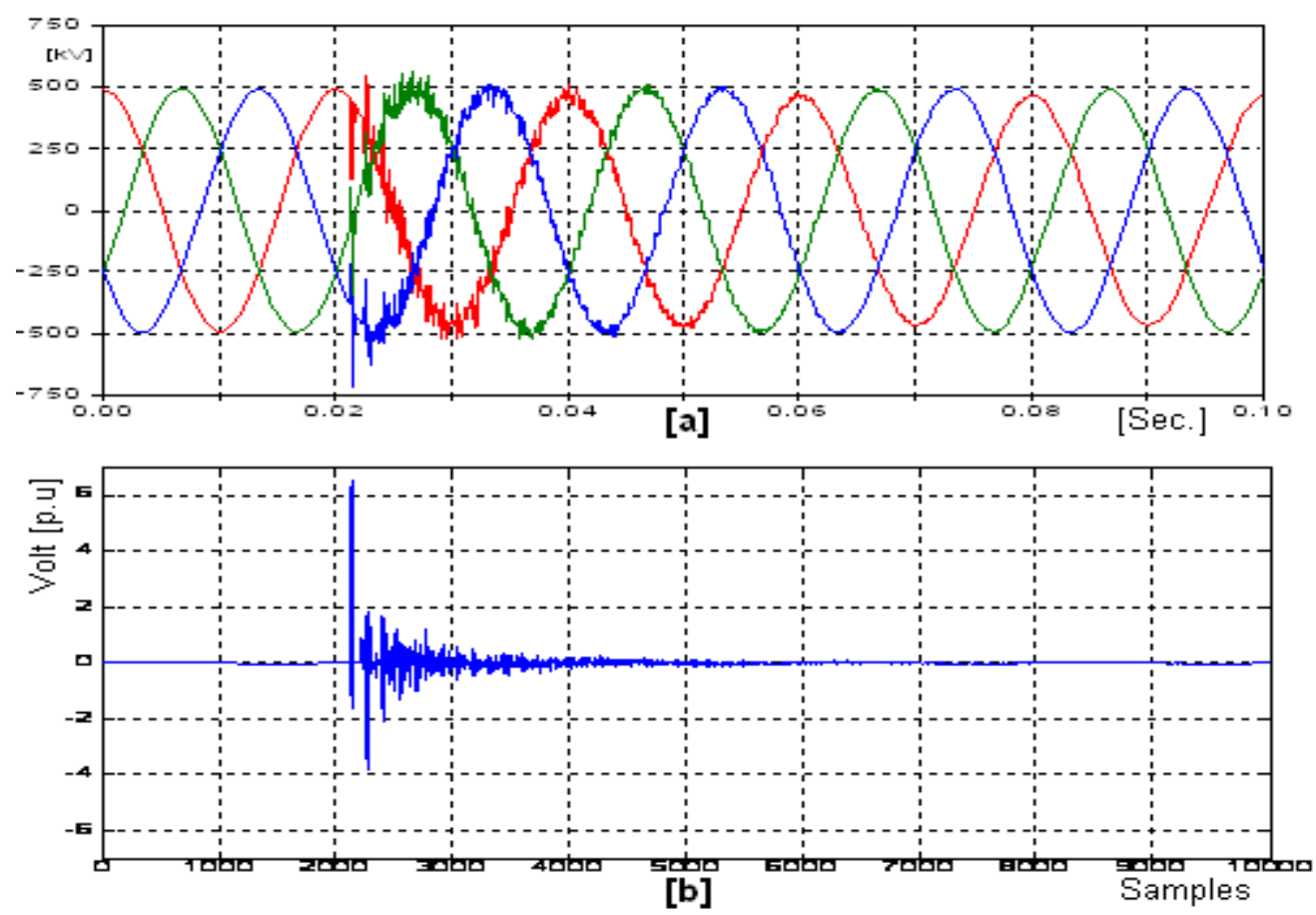

Fig.6 Simulation results for case study 3 Voltage waveform at B1
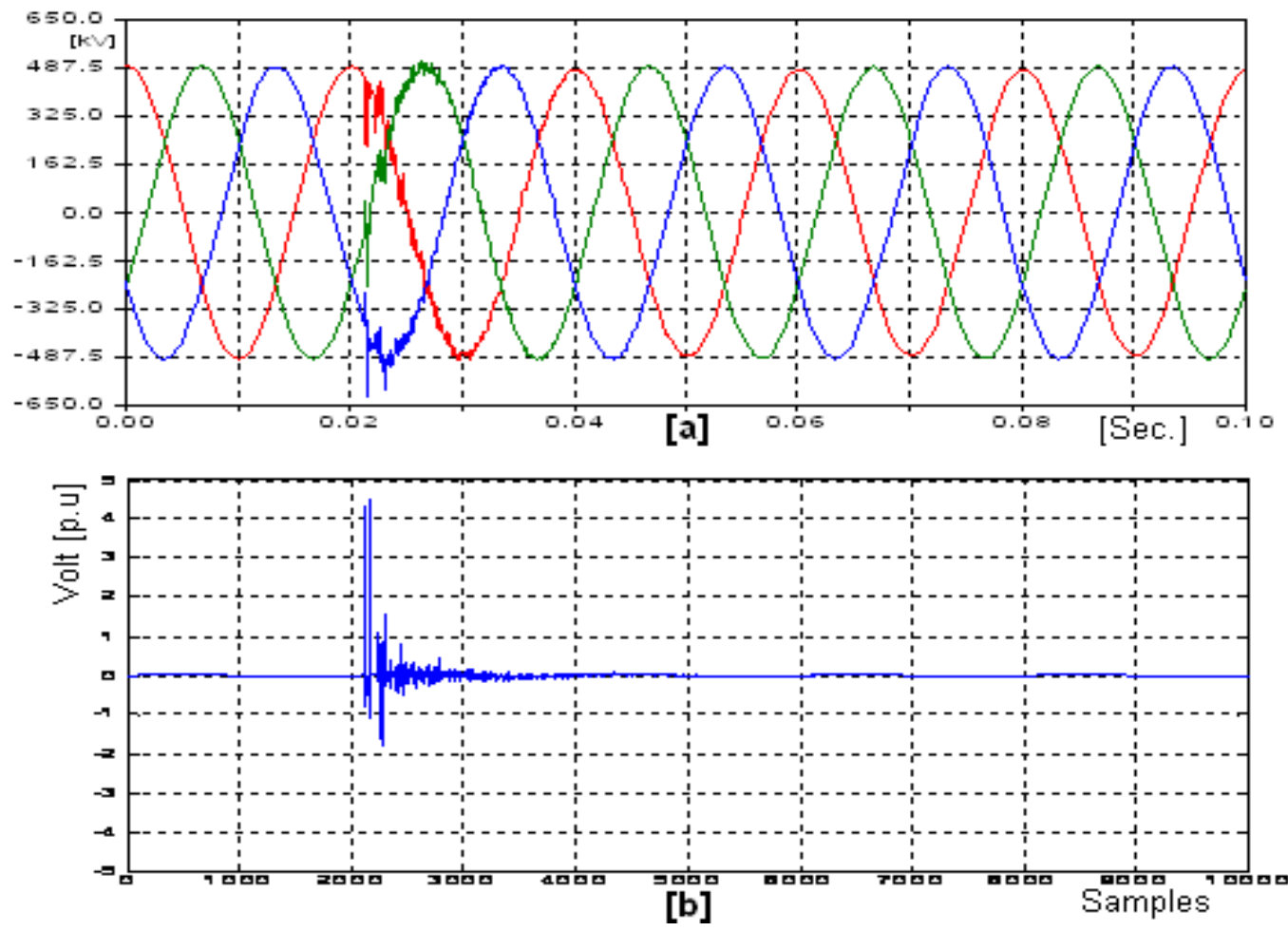

Fig.7 Simulation results for case study 4 Voltage waveform at B1 

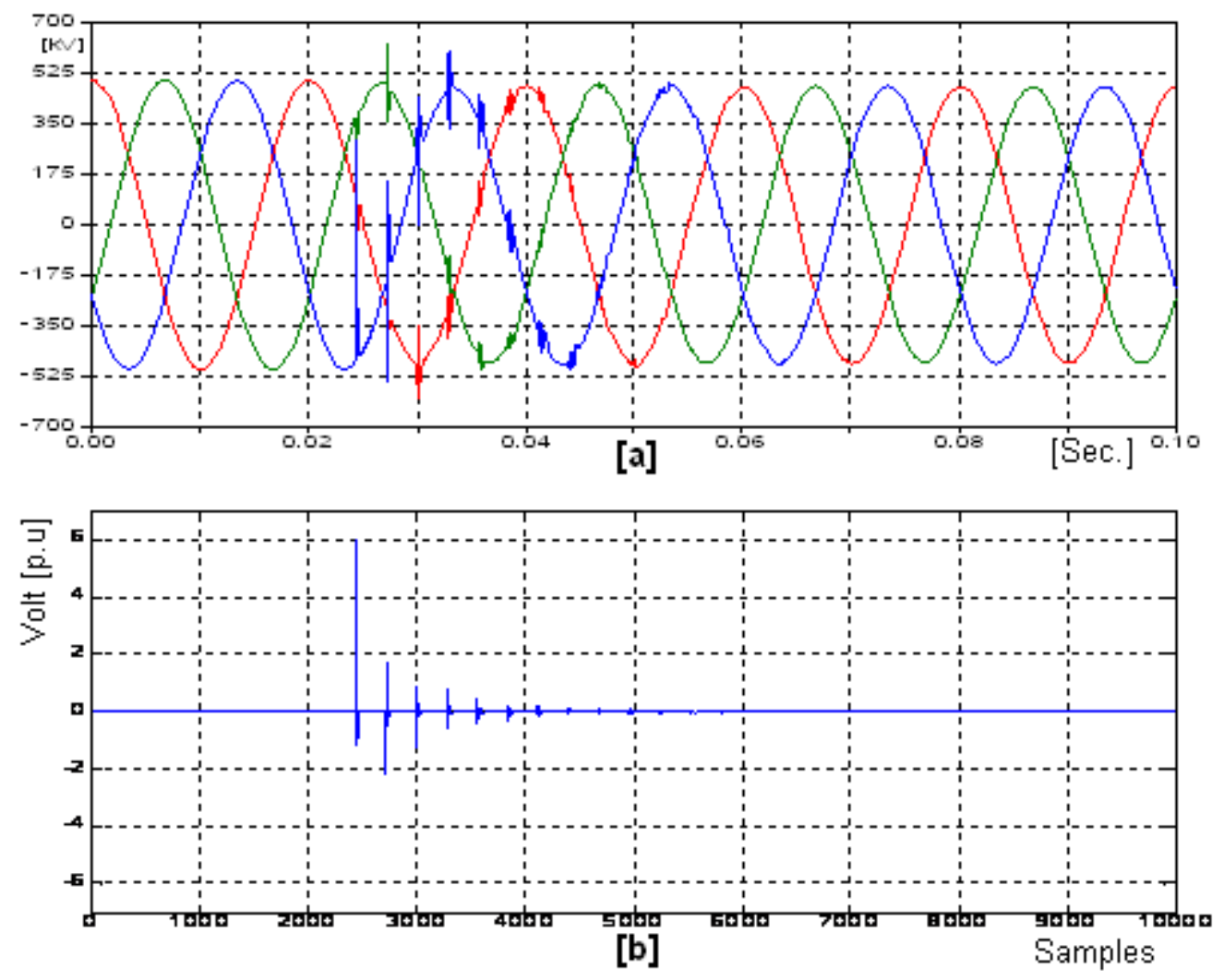

Fig. 8 Simulation results for energized line
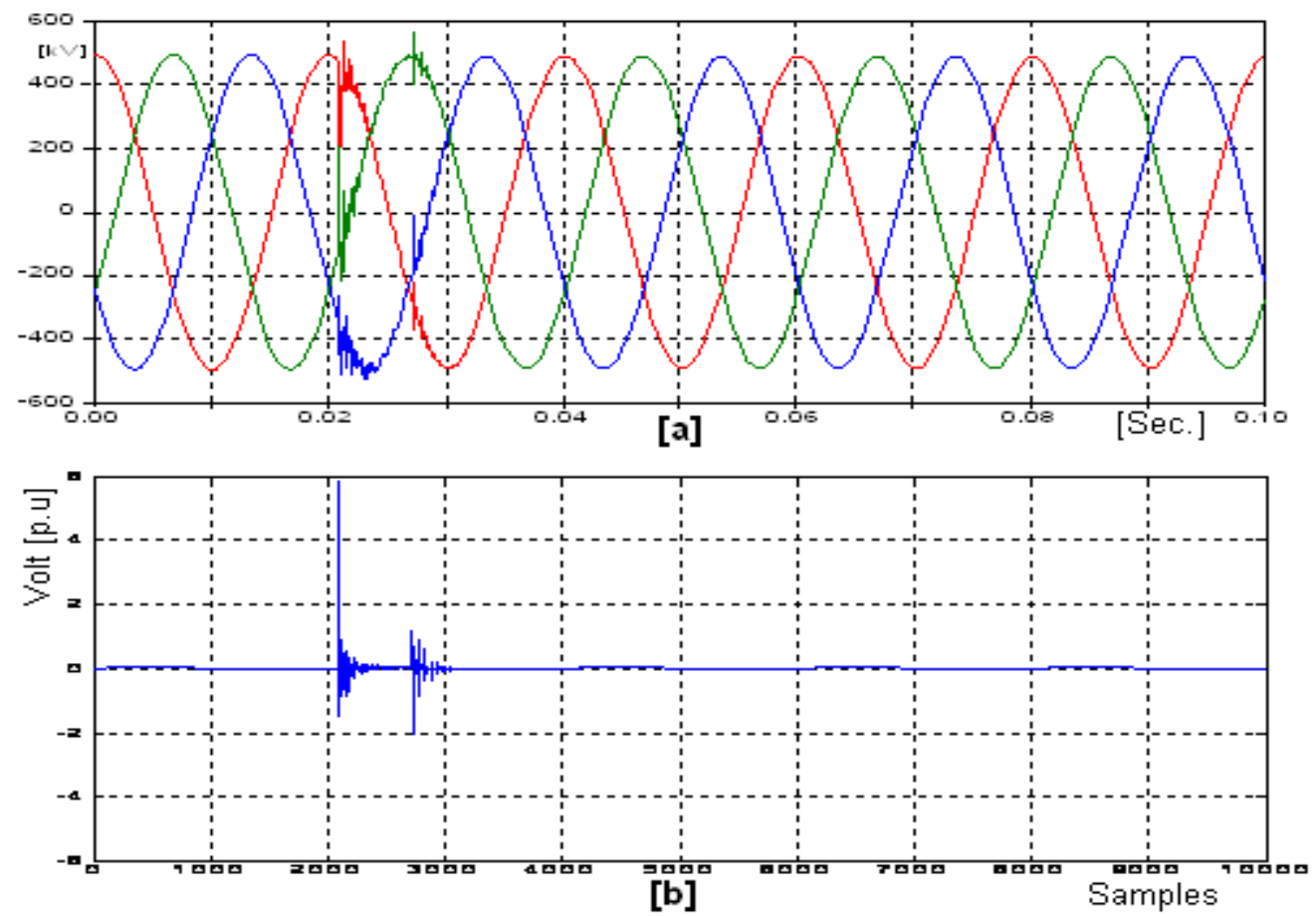

Fig. 9 Simulation results for load switching 


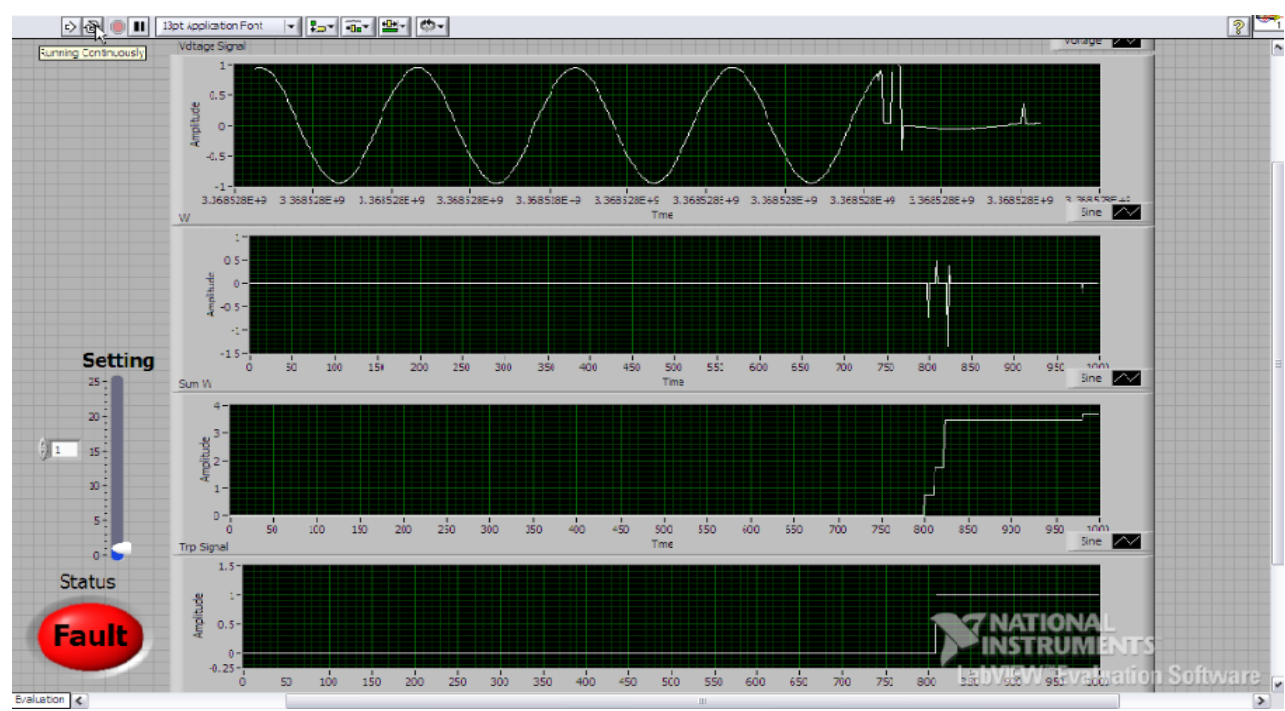

Fig.11 Relay response for SLG fault $(\mathrm{Rf}=20 \Omega, \mathrm{D}=25 \%$ of line length)

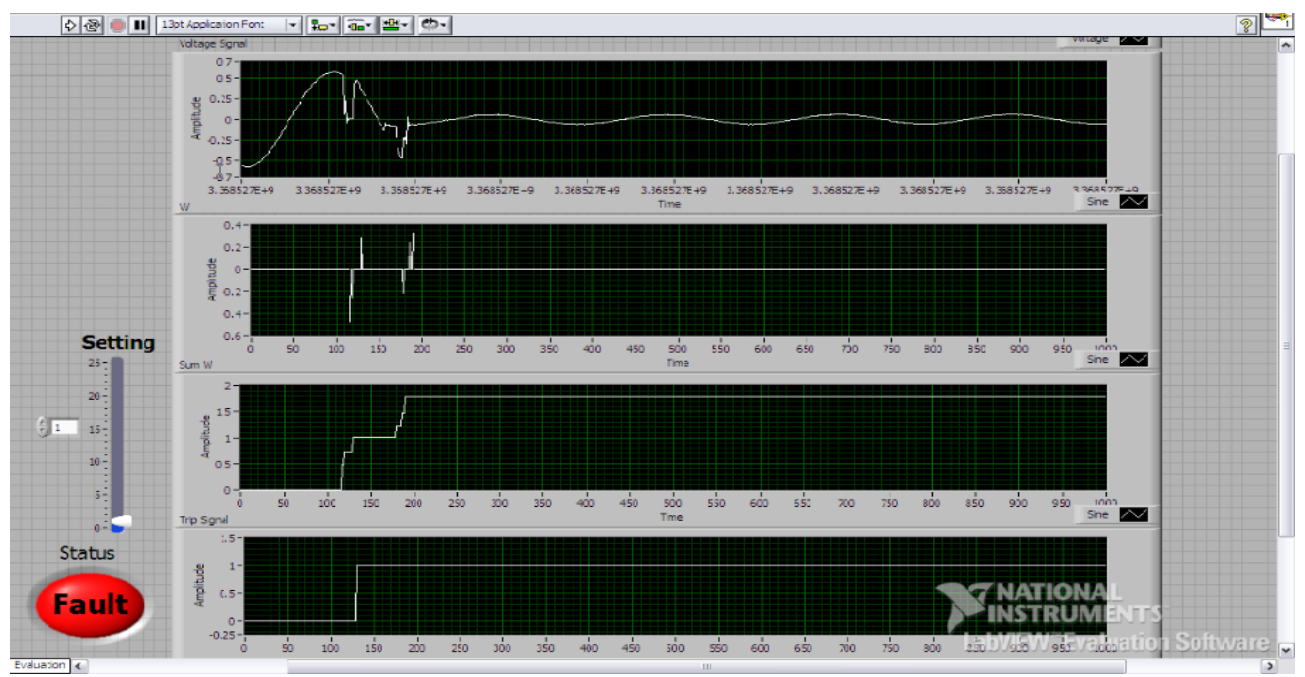

Fig.12 Relay response for SLG fault $(\mathrm{Rf}=15 \Omega, \mathrm{D}=50 \%$ of line length)

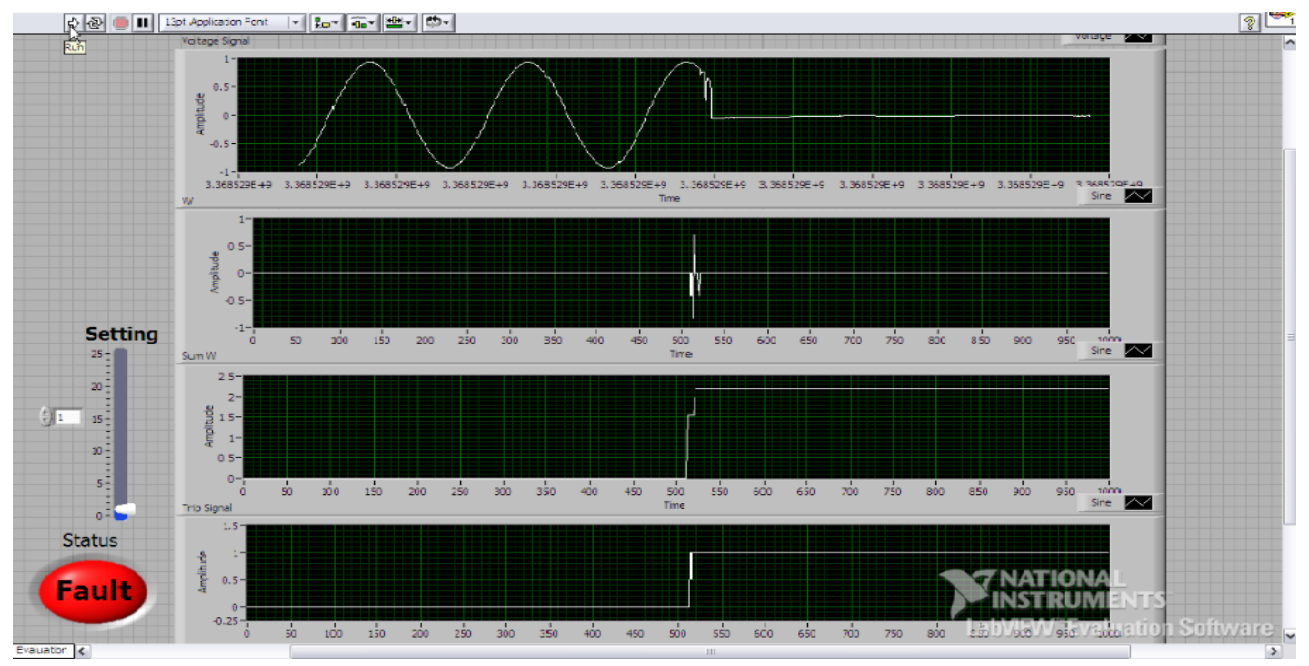

Fig.13 Relay response for SLG fault ( $\mathrm{Rf}=10 \Omega, \mathrm{D}=75 \%$ of line length) 